\title{
FE Model of the Fatih Sultan Mehmet Suspension Bridge Using Thin Shell Finite Elements
}

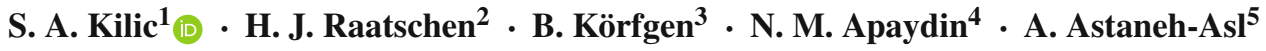

Received: 12 December 2015 / Accepted: 20 September 2016 / Published online: 1 October 2016

(C) The Author(s) 2016. This article is published with open access at Springerlink.com

\begin{abstract}
This paper presents the results of an eigenvalue analysis of the Fatih Sultan Mehmet Bridge. A highresolution finite element model was created directly from the available design documents. All physical properties of the structural components were included in detail, so no calibration to the measured data was necessary. The deck and towers were modeled with shell elements. A nonlinear static analysis was performed before the eigenvalue calculation. The calculated natural frequencies and corresponding mode shapes showed good agreement with the available measured ambient vibration data. The calculation of the effective modal mass showed that nine modes had single contributions higher
\end{abstract}

S. A. Kilic

skilic@boun.edu.tr

H. J. Raatschen

raatschen@fh-aachen.de

B. Körfgen

b.koerfgen@fz-juelich.de

N. M. Apaydin

napaydin@kgm.gov.tr

A. Astaneh-Asl

astaneh@berkeley.edu

1 Department of Civil Engineering, Bogazici University, 34342 Bebek, Istanbul, Turkey

2 Department of Mechanical Engineering, FH Aachen University of Applied Sciences, 52064 Aachen, Germany

3 Forschungszentrum Jülich $\mathrm{GmbH}$, Institute for Advanced Simulation, Jülich Supercomputing Centre, 52425 Jülich, Germany

4 Turkish Directorate of Highways, District 1, 34408 Kagithane, Istanbul, Turkey

5 Department of Civil and Environmental Engineering, University of California at Berkeley, Berkeley, CA 94720 , USA than $5 \%$ of the total mass. They were in a frequency range up to $1.2 \mathrm{~Hz}$. The comparison of the results for the torsional modes especially demonstrated the advantage of using thin shell finite elements over the beam modeling approach.

Keywords Suspension bridge $\cdot$ 3D nonlinear finite element model - Thin shell finite elements · Natural frequency . Effective modal mass

\section{Introduction}

Analyzing the dynamic response of long-span suspension bridges is a challenging task for bridge engineers. A great majority of the studies available in the literature employed beam elements to model the main, back-stay, and hanger cables and the towers and orthotropic deck structure.

The input parameters for the beam elements consist of the equivalent overall cross-sectional properties of the orthotropic deck and towers, such as the cross-sectional area, effective shear area, moments of inertia, and torsional constant. While the moments of inertia for bending can be approximated with a reasonable level of accuracy, determining the torsional constants for the towers and orthotropic deck structure with diaphragms is a difficult task. The orthotropic deck and towers can be approximated by using beam elements. Individual structural components such as the stiffener beams and diaphragms cannot be modeled directly by using beam elements.

The beam element models of suspension bridges require fine-tuning of the input parameters in order to match the ambient vibration test results. However, it is difficult to obtain matching results for the lateral, vertical, and torsional modes of vibration by using a limited set of equivalent overall cross-sectional properties. The accuracy of the beam 
models is reasonable for modes of vibration with lower frequencies and questionable for higher modes. In addition, the effects of a localized stress concentration cannot be modeled by using beam elements in advanced nonlinear dynamic analyses. Therefore, beam element models of suspension bridges have been restricted to studies on the global response.

The alternative approach proposed in this paper is to use shell elements in order to better represent the towers and deck structure of suspension bridges. This procedure allows the building of finite element (FE) models with fine resolutions by explicitly modeling the individual structural components of the towers and deck structure. The use of a shell element model removes the burden of estimating the equivalent overall cross-sectional properties of the orthotropic deck and towers. Shell element models provide better accuracy than beam element models not only for lower-frequency modes but also for the higher modes of vibration.

Brownjohn et al. [1,2] conducted ambient vibration tests on the Fatih Sultan Mehmet Suspension Bridge to measure the vertical, lateral, and torsional modes of the deck and towers up to a frequency of $2 \mathrm{~Hz}$. They employed auto power spectrum methods to identify the modal frequencies. They constructed numerical models employing beam elements and concluded that the measured and computed values agreed well at low frequencies [3]. However, they observed an increasing divergence at higher frequencies. Abdel-Ghaffar and Stringfellow [4] investigated the dynamic response of suspension bridges and concluded that a relatively large number of modes are necessary to obtain a reasonable representation of the lateral response, which is similar to the case for vertical response analysis.

Apaydin studied the dynamic response of the Fatih Sultan Mehmet Bridge and employed a three-dimensional FE model with beam elements $[5,6]$. The agreement between the finite element results and measured ambient vibrations in the experiment was better for the lateral and vertical modes than for the torsional modes because of the difficulty with representing the orthotropic deck structure having diaphragms by using beam elements.

Daniell and Macdonald [7] applied model updating techniques with systematic manual tuning to develop FE models of cable-stayed bridges. Their FE model employs shell elements for the reinforced concrete slab and beam elements for the orthotropic steel box section deck. They pointed out the difficulties of modeling the orthotropic deck with many internal components when using beam elements.

Zhang et al. [8] studied the ambient vibrations on suspension bridges and compared the measured data with the results of FE models that utilized a combination of beam and shell elements. They emphasized the contribution of the towers to the overall response of the bridge and identified the tower modes up to a frequency of $7.7 \mathrm{~Hz}$ from the measured data.
In most of these studies, some of the bridge components were simplified. The orthotropic deck structure with internal diaphragms was often modeled with beam elements. The tower motion was sometimes neglected or approximated with the use of beam elements that only approximately represented the stiffness of the internal tower diaphragms and stiffener beams. The equivalent cross-sectional properties required fine-tuning in order to match the ambient vibration test measurements.

Few suspension bridge studies that employed shell elements can be found in the open literature. Rahbari and Brownjohn built two FE models consisting of beam and shell elements for the Humber Bridge [9]. They compared the numerical results with the available experimental data. They modeled the deck structure with equivalent plate elements in the low-resolution model. They provided an alternative modeling approach with equivalent box sections in the highresolution model. They concluded that the low-resolution model was inadequate in terms of matching the measured modal frequencies of the bridge and emphasized the need for high-resolution models to conduct dynamic studies.

Most finite element models of suspension bridges have low mesh resolutions and employ mainly beam elements. Karmakar et al. modeled the Vincent Thomas Suspension Bridge using shell elements only for the 165 -mm-thick reinforced concrete deck, and a combination of beam and truss elements for all other components of the structural system [10]. The FE model consisted of 4913 beam elements and 6800 shell elements. They validated the finite element model by comparing the computed eigenproperties of the bridge with the system identification results obtained using ambient vibration data. Duan et al. [11] provided a detailed FE model for the Tsing Ma Suspension Bridge. They compared the numerical results with the measured data from the ambient vibrations tests. The FE model consisted of half a million beam, shell, and hexahedral elements. They modeled the structural components of the deck in detail instead of using beam elements with approximate cross-sectional properties. Rocker bearings of the bridge were incorporated directly into the FE model. They emphasized the need for FE models with high resolution in order to carry out health monitoring studies that require the identification of critical locations and components.

In this study, shell elements were employed to model the geometry and internal structural components of the towers and orthotropic bridge deck of the Fatih Sultan Mehmet (FSM) Bridge located in Istanbul, Turkey. Only the suspension, back-stay, and hanger cables were modeled with beam elements. The modus operandi of the current study avoided the need for fine-tuning the approximate crosssectional properties. The dynamic analysis was preceded by a nonlinear static analysis that required the establishment of the correct tensile forces in the cables and the converged 
equilibrium geometry of the structure after the application of the dead and live loads.

The objective of this study was to build a high-resolution FE model of the FSM Bridge. This FE model was applied to calculating the eigenmodes of the FSM Bridge using the commercial finite element software LS-DYNA [12] and was validated by comparing the results, i.e., mode shapes and frequencies, with ambient vibration experimental data that are available in the open literature. It will be used in further studies for nonlinear dynamic analyses that employ the direct time integration schemes.

\section{Articulation of Fatih Sultan Mehmet Suspension Bridge}

The Fatih Sultan Mehmet (FSM) Bridge crosses the Bosporus Straits at Istanbul, Turkey, and has coordinates of $41^{\circ} 5^{\prime} 28^{\prime \prime} \mathrm{N}$, $29^{\circ} 3^{\prime} 40^{\prime \prime} \mathrm{E}$. It was opened to traffic on July 3, 1988. The FSM Bridge is an important part of the Trans-European Motorway. The daily traffic load on the bridge is approximately 200000 vehicles. The bridge is a critical part of the city's infrastructure and should remain operational after a large seismic event for relief efforts. The city of Istanbul is located in a highly active seismic region, which necessitates the careful evaluation of the dynamic characteristics of the FSM Bridge.

The FSM Bridge is a gravity-anchored suspension bridge with a length of $1090 \mathrm{~m}$ (Fig. 1a). The bridge deck has an aerodynamic cross section similar to the Severn Bridge in England (span of $988 \mathrm{~m}$ ), First Bosporus Bridge in Istanbul (span of $1074 \mathrm{~m}$ ), and Humber Bridge in England (span of $1410 \mathrm{~m}$ ). The $3 \mathrm{~m}$ high and $39.40 \mathrm{~m}$ wide bridge deck is a hollow steel box composed of orthotropic stiffened panels (Fig. 1b). Diaphragm wall panels are present in the deck structure at approximately every $4 \mathrm{~m}$. Two steel towers (Fig. 1c) with a height of $107.1 \mathrm{~m}$ support the suspension cables. Each suspension cable is connected to the bridge deck with 60 vertical hanger cables at intervals of $17.92 \mathrm{~m}$. The diameter of the suspension cable in the main span is $0.77 \mathrm{~m}$. The maximum suspension cable force at the top of the towers is $181 \mathrm{MN}$. The diameter of the back-stay cable is $0.80 \mathrm{~m}$ and supports an axial tensile force of $200 \mathrm{MN}$. The deck, towers, and cables have masses of 16960, 6820, and $10250 \mathrm{t}$, respectively [13]. The bridge was designed according to the provisions of the British Standard with some modifications according to the Japanese Industrial Standards.

The base of each tower leg is embedded in the reinforced concrete foundation to fix the towers at the base. The saddles are fixed to the top of the towers. Figure 2 a shows a schematic of the relevant structural components at both ends of the main span. A single wind shoe-also called a shear key-connects the end segment of the steel deck to the top of the reinforced concrete pier as illustrated in Fig. 2b. The wind shoe only restrains the transverse movement of the bridge. In addition, two rocker bearings connect the deck to the reinforced concrete pier at each end. A single rocker bearing is shown in Fig. 2c. The two rocker bearings at each end resist the vertical movement of the end girder and provide torsional restraint at each end of the bridge. Figure $2 d$ shows the bottom plate of the end girder, concrete pier, wind shoe, and one of the rocker bearings. Additionally, expansion joints are located at both ends of the main span, separating the deck from the side spans. Their only purpose is to carry the traffic to and from the bridge, and they have no capacity to guide or restrain any movement of the deck.

\section{Finite Element Model of FSM Bridge}

A full three-dimensional FE model [14] of the bridge with cables, a deck body, and towers including all stiffeners was considered for computation with the established finite element software LS-DYNA [12] (Fig. 3). All steel plates were modeled with shell finite elements based on the corresponding thickness values available in the design documents [13]. The curvature of the deck along the longitudinal direction of the bridge was modeled; this is important for the coupling of the lateral and torsional modes.

The deck and the towers are hollow box structures consisting of steel plates with stiffener plates. The four-node thin shell finite elements offered the most detailed choice for modeling the individual steel plate components of the deck and towers, including all of the stiffener plates. Figure $4 \mathrm{a}$ shows the mesh of a tower section with the floors and stiffener plates. The tower is reinforced with vertical stiffener plates placed perpendicular to the main plates. The tower leg has 40 floors along the height and was modeled with about 13800 shell elements. The four saddle masses, each of about $10 \mathrm{mt}$, were included as rigid bodies between the top and main suspension cable. The rigid connection of tower legs to the solid rock is defined by fixed constraints at the tower base. The bridge deck is made up of 62 segments welded together. The typical span length is $17920 \mathrm{~mm}$. Figure 4b shows a transparent view of the FE model for an individual deck segment with diaphragms and stiffeners. Table 1 shows the elastic material properties necessary for the eigenvalue analysis, while Table 2 covers the range of cross-sectional properties for structural members.

Figure 5a shows a photograph taken inside the deck structure, and Fig. 5b is the corresponding FE model. Each of the 62 segments required about 7100 shell elements to model all significant components like the stiffeners of the steel construction. The mass of the asphalt road cover was taken into account.

The twin hanger cables were modeled as a single cable by using the resultant cross-sectional area. The main cables, the 
Fig. 1 Fatih Sultan Mehmet (FSM) Bridge. a Span dimensions of FSM Bridge (all dimensions are in $\mathrm{mm}$ ) $\mathbf{b}$ Deck dimensions of FSM Bridge c

Tower dimensions and elevations of FSM Bridge

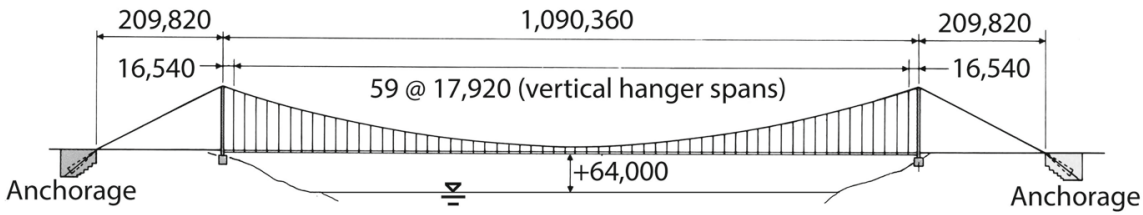

(a)

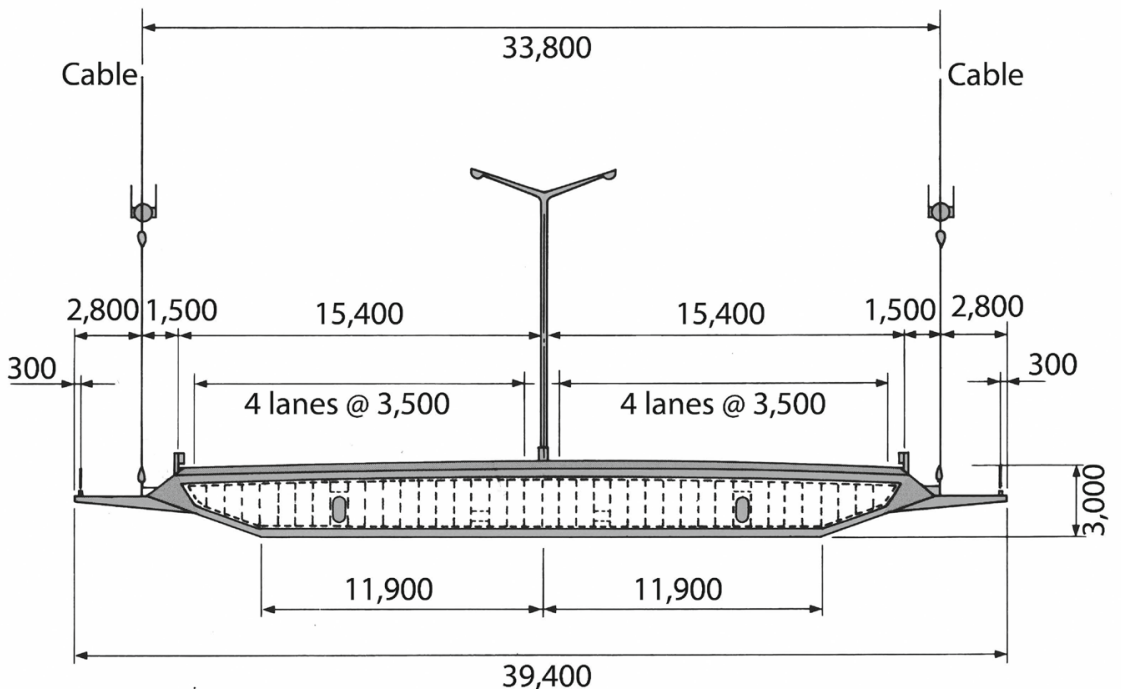

(b)

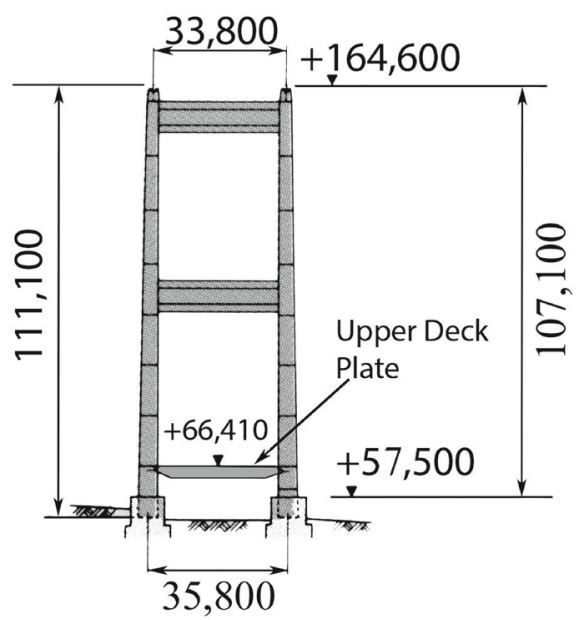

(c)

back-stay cables, and all hanger cables were modeled with beam elements. Each hanger cable was meshed with five elements, and each main cable had 61 elements. Each backstay cable used 40 elements to model the cable sagging. The reduced axial stiffness of twisted cables is taken into account by the reduction of Young's modulus (Table 1).

The rocker bearing with the I-shaped cross section was modeled with shell elements. The end plates of the rocker bearings had hinge connections to the deck and ground in order to limit the uplift and downward push of the deck on each end of the bridge. Due to the presence of two rocker bearings, the torsional motion was also constrained. The wind shoe consists of two triangular frameworks. The slender framework members were modeled with beam elements. The structural components that attach the wind shoe to the pier and bottom plate of the deck girder were modeled with shell elements. The hinge connections to the deck, pier, and between each framework allowed the longitudinal and vertical motions of the deck, while restricting the lateral motion. All cross-sections were taken from the design 


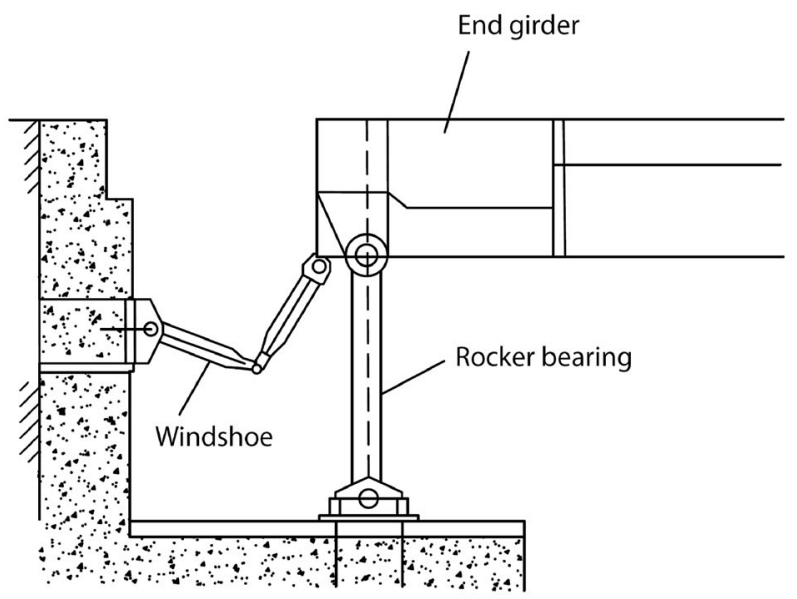

(a)

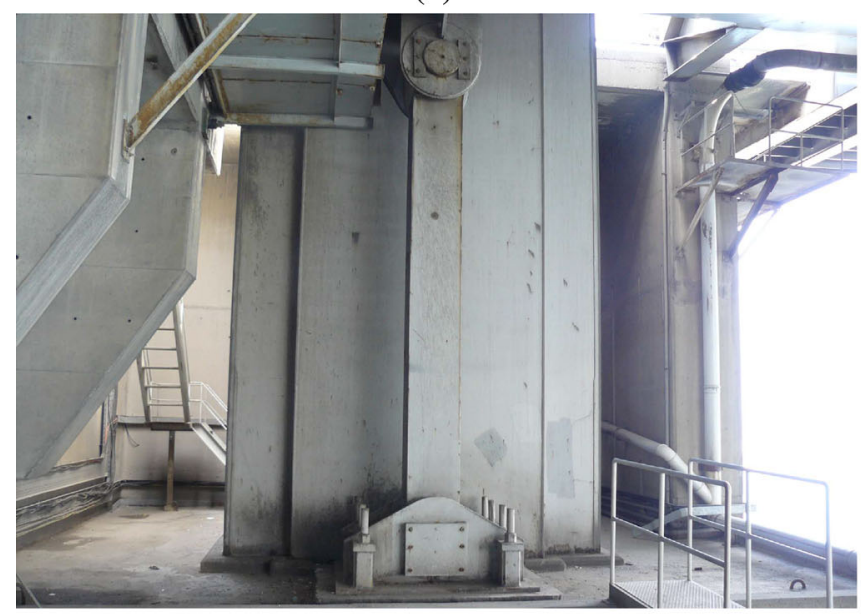

(c)

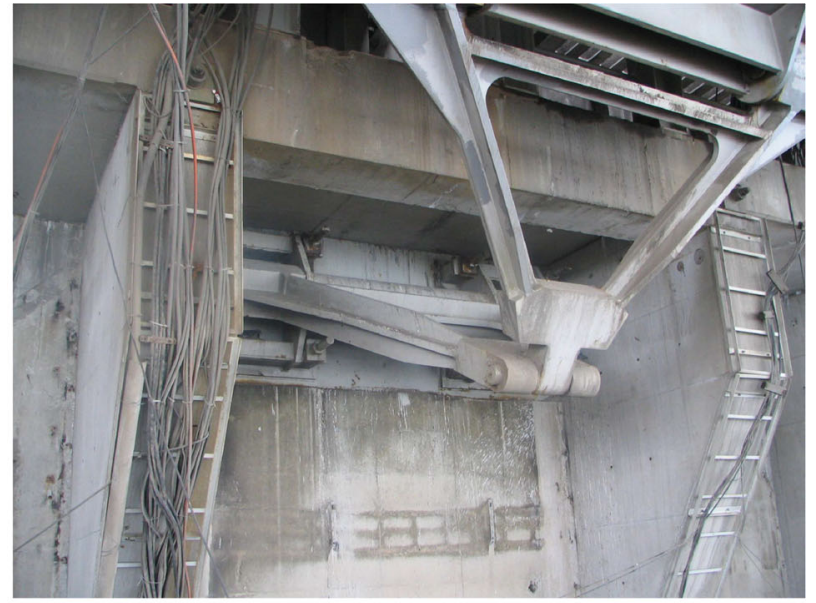

(b)

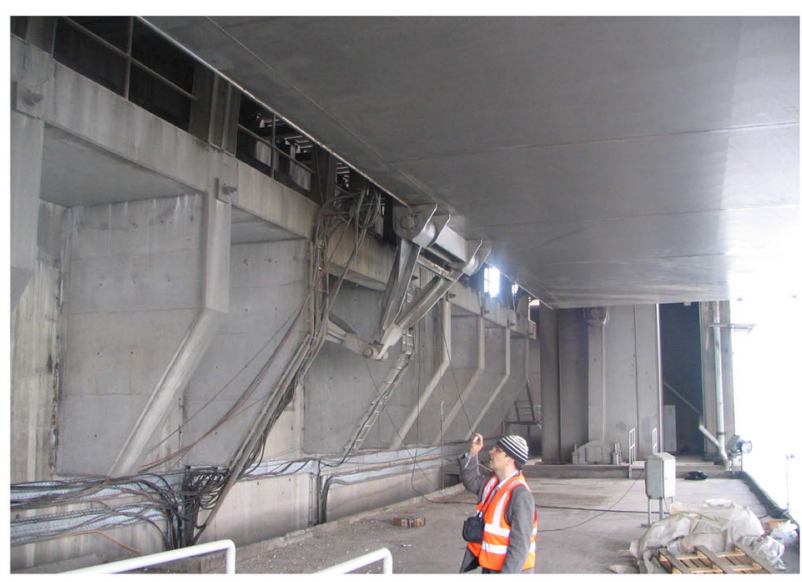

(d)

Fig. 2 Support at the end of main span: a schematic view of the components, $\mathbf{b}$ wind shoe, $\mathbf{c}$ rocker bearing, and $\mathbf{d}$ overall view of the end girder

Fig. 3 3-D finite element model of FSM Bridge modeled with beam and shell elements

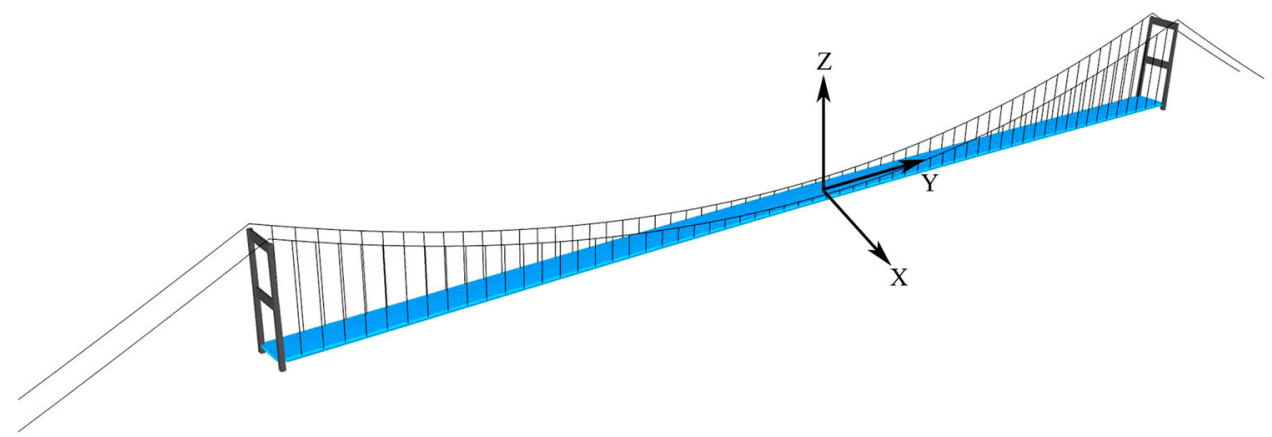

documents [13]. Figure 6 illustrates the FE model of the end girder with the two rocker bearings and wind shoe, and can be compared with the structural components shown in the photograph of Fig. 2d.

The structural components that are of importance to the eigenmodes of the bridge were modeled in detail. Other components were modeled in an effective manner without compromising the accuracy of the current study. The ground anchorage of the towers and back-stay cables as well as the connections of the wind shoes to the concrete piers were modeled by employing kinematic boundary conditions. The expansion joint, which is located between the end of the deck and side span, was not included in the finite element model since it has no effect on the eigenmodes of the bridge. Furthermore, the gap between the main deck and tower is smaller than the distance between the deck and side spans. Therefore, the dynamic motion of the deck is limited by the towers, and not by the expansion joint. 
Fig. 4 FE model of tower and deck parts. The skin is transparent in order to show the stiffener plates inside. a Tower section with stiffeners and floors. b Single deck segment with runway, sideway,

diaphragms, and stiffeners

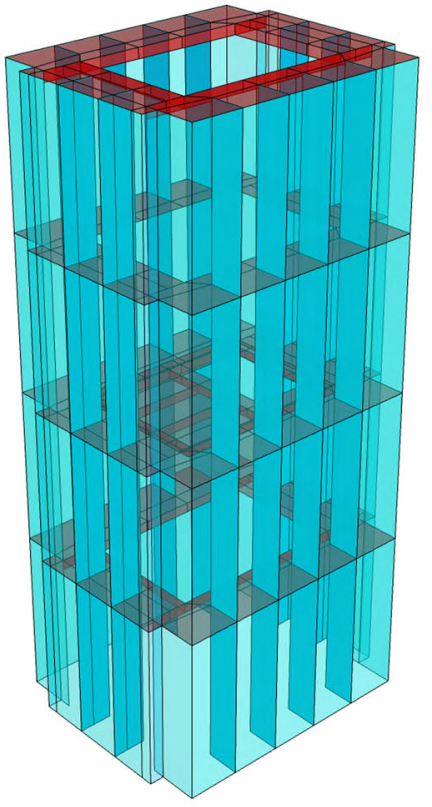

(a)

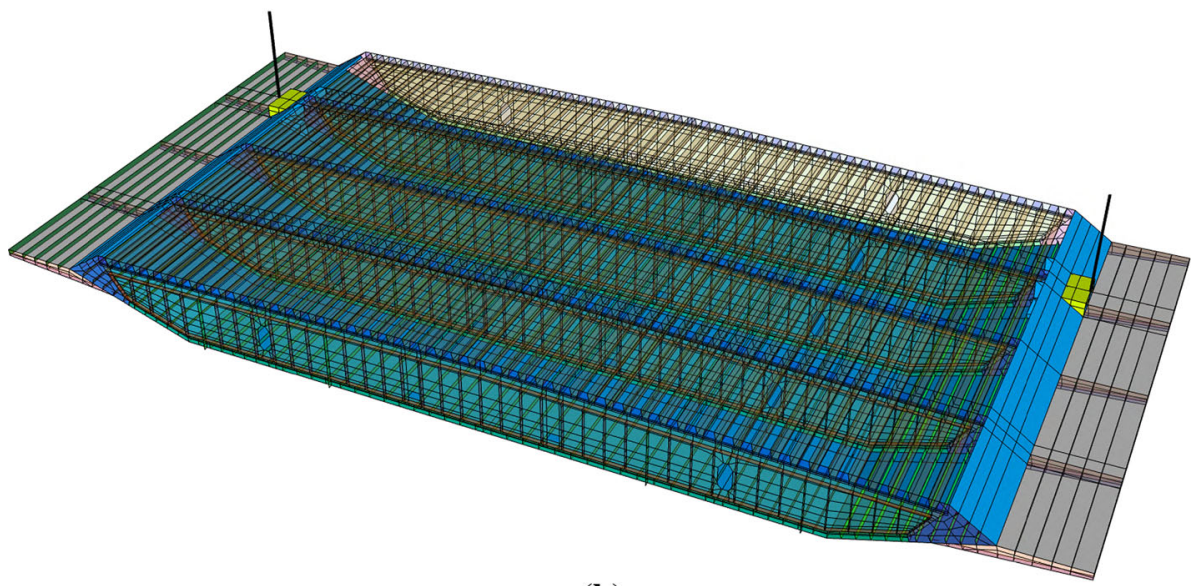

(b)

\begin{tabular}{llll}
\hline & Density $\left(\mathrm{kg} / \mathrm{m}^{3}\right)$ & Young's modulus $(\mathrm{MPa})$ & Poisson's ratio \\
\hline Deck & 8680 & 210,000 & 0.3 \\
Tower & 8680 & 210,000 & 0.3 \\
Main cable & 8530 & 189,300 & 0.3 \\
Back-stay cable & 8530 & 189,300 & 0.3 \\
Hanger cable & 8530 & 89,100 & 0.3 \\
\hline
\end{tabular}

Table 2 Cross-sectional properties

\begin{tabular}{lllr}
\hline & $\begin{array}{l}\text { Thick. of outer plates } \\
t_{\min }-t_{\max }(\mathrm{mm})\end{array}$ & $\begin{array}{l}\text { Thick. of stiffener plates } \\
t_{\min }-t_{\max }(\mathrm{mm})\end{array}$ & $\begin{array}{l}\text { Area } \\
\left(\mathrm{mm}^{2}\right)\end{array}$ \\
\hline Deck & $10-14$ & $8-16$ & \\
Tower & $60-63$ & $12-20$ & 366,160 \\
Main cable & & & 391,301 \\
Back-stay cable & & & 5064 \\
Hanger cable & & & \\
\hline
\end{tabular}




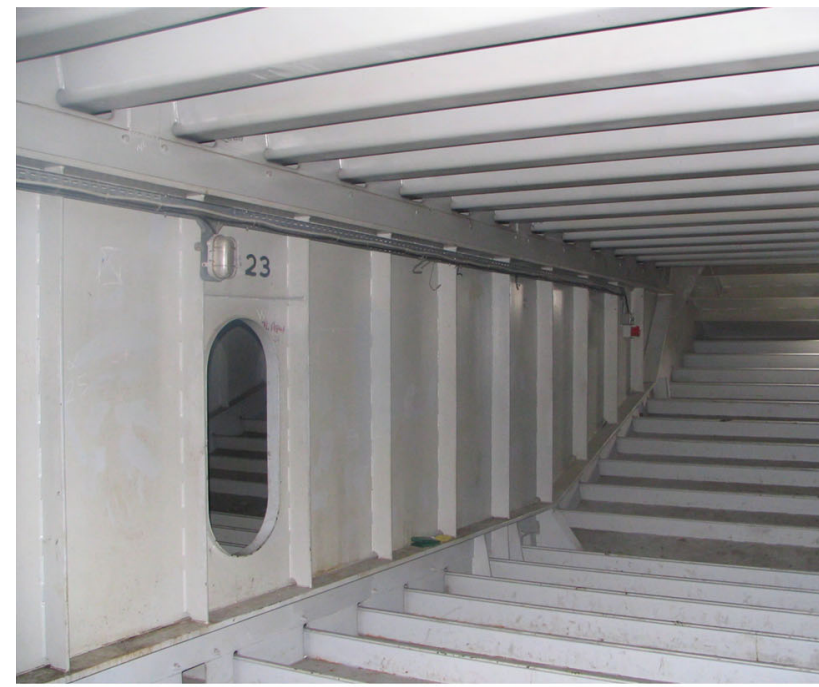

(a)

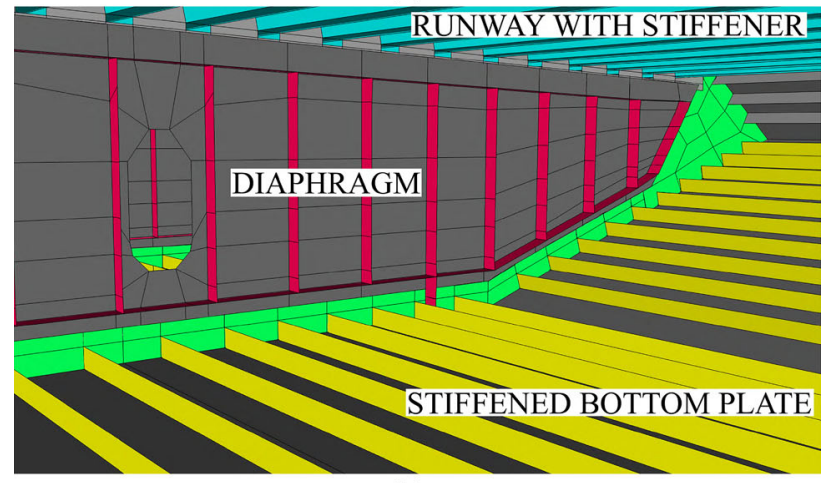

(b)

Fig. 5 Deck box with diaphragm and stiffeners. a Photograph from FSM Bridge. b Corresponding FE model used in this investigation

All shell elements were Belytschko-Tsay elements [12, $15]$ with two integration points in the thickness direction. The beam elements were Hughes-Liu elements [12,16,17] with a tubular cross section and $2 \times 2$ cross section integration points. The present model had approximately 465000 nodes and 500000 shell elements and was sufficient to resolve even the smallest load-carrying component used in the design of the FSM Bridge.

The geometry of the FE model was generated from the blueprints [13] that showed the bridge construction under a dead load. Applying gravity to this model gave a center deflection of $8.6 \mathrm{~m}$ due to the cable elongation and displacement. To achieve the dead-load configuration, the cable elongation was eliminated by pre-straining. In addition, a total live load of $2000 \mathrm{t}$ was applied to account for the extra weight of vehicles under normal traffic conditions (about $25 \%$ of the design live load) [13]. The ambient vibration measurements of Brownjohn et al. [1] were done under normal traffic conditions, which motivated this choice for the live load. Because of the small ratio of the live load to the dead load, the influence of the live load on the overall behavior of the bridge is negligible. The result of this nonlinear static analysis was that the shape of the bridge under gravity was correctly determined. The calculated cable forces, back-stay cable sag of about $0.9 \mathrm{~m}$, and bending displacements of the towers fit the published values [5]. The following eigenvalue analysis started from this pre-strained model, including the geometric stiffness matrix.

The FE method calculations for the FSM Bridge model were carried out by using the software package LS-DYNA 971 Release 5.1.1 from Livermore Software Technology Corporation, California [12]. The nonlinear static analysis applying the gravity load and cable pre-straining was performed with LS-DYNA's full Newton iterative solver [12]. The gravity load and pre-straining of the cables were applied synchronously in order to converge to the pre-stressed deadload configuration of the bridge. The solution of the linear eigenvalue problem for this converged equilibrium geometry was determined by using LS-DYNA's block shift and the inverted Lanczos eigensolver [18] from BCSLIB-EXT [19].

\section{Numerical Results of Modal Analysis}

The accuracy of the FE model was calculated by comparing the numerical results and ambient vibration measurements. Several papers have discussed experimental results for the FSM Bridge $[1,5,6]$. The most detailed results from ambient vibration tests were given by Brownjohn et al. They measured modes in the range of $0-2 \mathrm{~Hz}$ and provided frequencies and mode shapes up to $1.0 \mathrm{~Hz}$ [1]. They developed auto power spectrum plots that allow modes to be identified with frequencies of up to $1.6 \mathrm{~Hz}$ but only listed selected mode shapes for frequencies between 1.0 and $1.6 \mathrm{~Hz}$.
Fig. 6 FE modeling of the end girder, two rocker bearings, and wind shoe at each end of the bridge

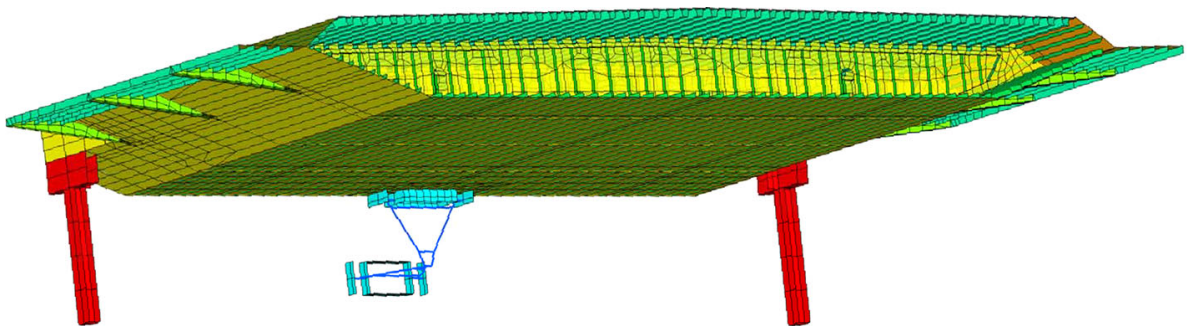


Brownjohn et al. measured different types of modes (i.e., deck, tower, and cable) in separate experimental setups, which made identifying unique coupled modes difficult sometimes. However, coupling between modes is inevitable for the FSM Bridge because the slight curvature of the deck couples the lateral and torsional modes. In addition, lateral tower modes are always connected with lateral deck modes, and longitudinal tower modes are related to the vertical deck motion. Having the entire mode shape available makes it easier for an analyst to classify coupled mode shapes in a numerical study, whereas the same classification can be difficult in an experimental study.

The following sections discuss the deck and tower modes in detail. The comparison with experimentally identified modes showed the overall high quality of the presented bridge model. Emphasis was placed on modes that were significant to the behavior of the bridge. The effective modal mass allowed these modes to be identified, and the Sect. 5 is dedicated to this discussion.

In addition to the structurally important deck and tower modes, the degrees of freedom of the cables gave rise to many cable modes. The lateral and vertical motions of the deck were always related to the lateral and vertical motions of the main cable. The lateral and longitudinal motions of the towers were related to the movement of the back-stay cable. There were many modes that purely consisted of the motions of the main, back-stay, and hanger cable modes. The frequencies for the back-stay and hanger cables closely agreed with the analytical formula for pre-stressed strings. The hanger and back-stay cables could move in both lateral directions. Because of the double symmetry of the bridge, multiple hanger and back-stay cable modes existed.

All of the different types of cable modes were inevitably calculated to obtain the solution of the eigenvalue problem for this bridge model, which greatly increased the number of modes. Because they are not important to the structural behavior of the bridge, they will not be discussed any further in this paper.

\subsection{Lateral deck modes}

Figures 7, 8, 9 and 10 show four different kinds of mode shapes for the deck motion. The first lateral deck mode $f_{1}$ is illustrated in Fig. 7. This mode, which is the lowest eigenmode of the FSM Bridge, showed a symmetric displacement with respect to the xz-plane of this model's coordinate system (Fig. 3), and the deck motion was synchronous to the motion of the main cables. Table 3 compares the numerical results for the first eight lateral deck modes with the experimental eigenfrequencies measured by Brownjohn et al.

The relative errors $\left(f_{\exp }-f_{\text {num }}\right) / f_{\exp }$ were less than $12.2 \%$. Brownjohn et al. [1] reported that the measured acceleration signals were at least one order of magnitude smaller

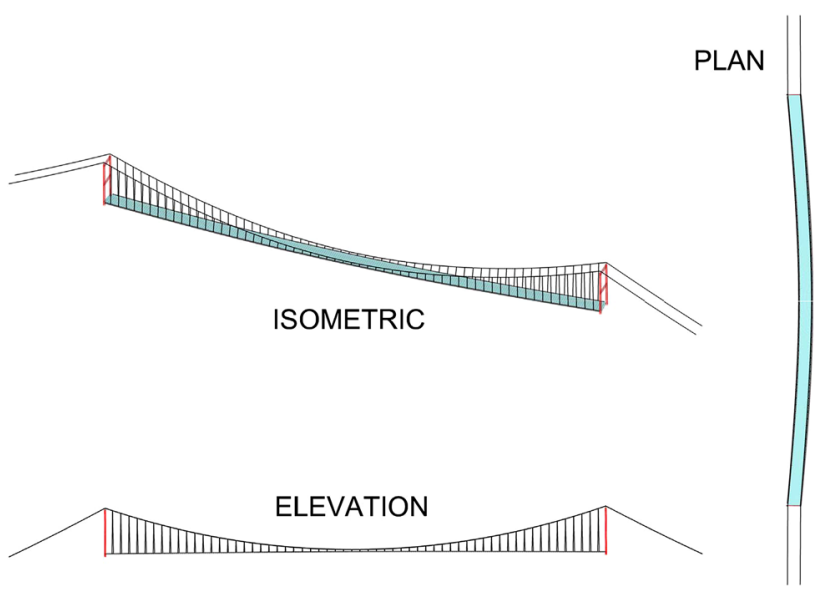

Fig. 7 Mode $f_{1}$, Freq. $0.072 \mathrm{~Hz}$ : lateral mode with dominant deck motion, displacements are scaled to show the characteristics of the modes

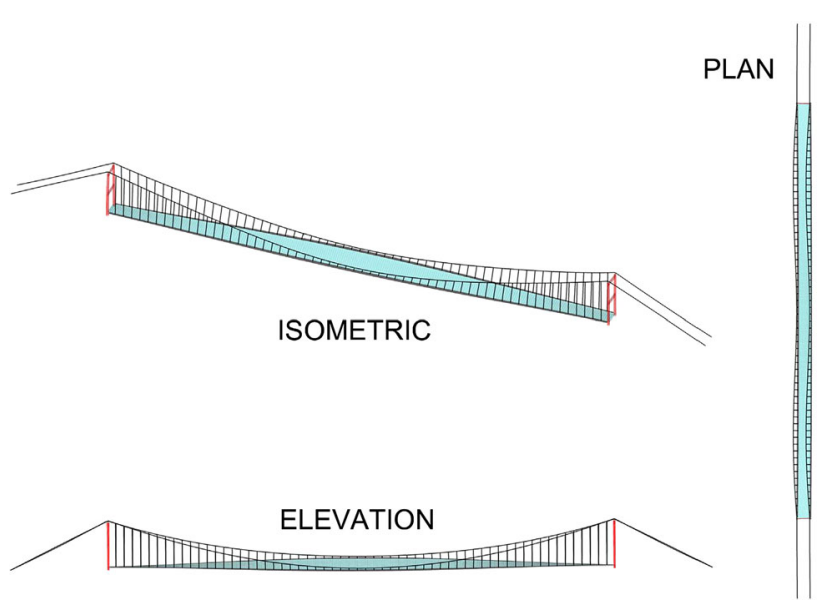

Fig. 8 Mode $f_{11}$, Freq. $0.29 \mathrm{~Hz}$ : torsional mode with dominant deck motion, displacements are scaled to show the characteristics of the modes

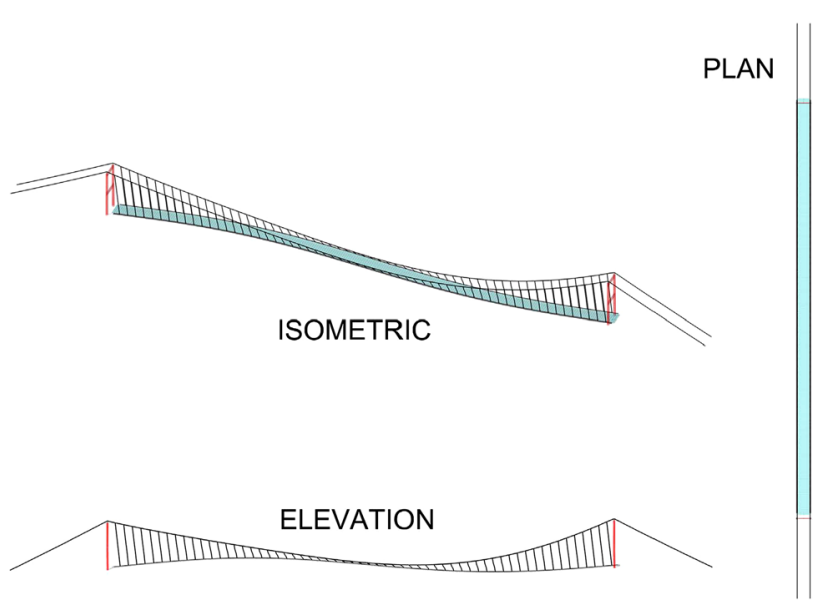

Fig. 9 Mode $f_{2}$, Freq. $0.106 \mathrm{~Hz}$ : vertical/longitudinal mode with dominant deck motion, displacements are scaled to show the characteristics of the modes 


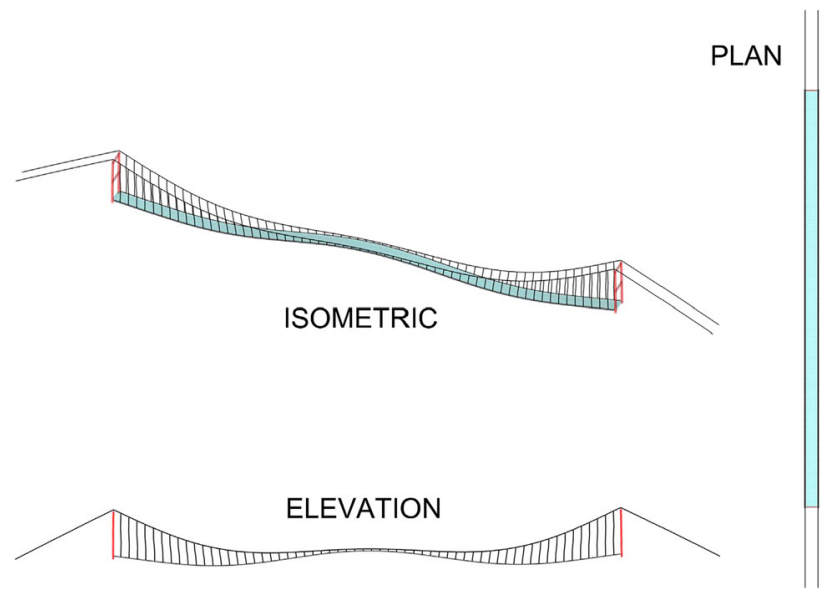

Fig. 10 Mode $f_{5}$, Freq. $0.206 \mathrm{~Hz}$ : vertical mode with dominant deck motion, displacements are scaled to show the characteristics of the modes

Table 3 Comparison of calculated lateral deck modes with experiments

\begin{tabular}{|c|c|c|c|c|}
\hline \multicolumn{2}{|c|}{ Measured modes } & \multicolumn{2}{|c|}{ Numerical analysis } & \multirow{2}{*}{$\begin{array}{l}\text { Rel. error } \\
(\%)\end{array}$} \\
\hline$f_{\exp }(\mathrm{Hz})$ & Mode & $f_{\text {num }}(\mathrm{Hz})$ & Mode & \\
\hline 0.077 & L1 & 0.072 & $f_{1}$ & 6.6 \\
\hline 0.239 & L2 & 0.210 & $f_{6}$ & 12.2 \\
\hline 0.287 & L4 & 0.286 & $f_{9}$ & 0.4 \\
\hline 0.315 & L5 & 0.295 & $f_{12}$ & 6.2 \\
\hline 0.432 & L6 & 0.398 & $f_{16}$ & 7.8 \\
\hline 0.466 & L7 & 0.468 & $f_{18}$ & -0.4 \\
\hline 0.504 & L8 & 0.476 & $f_{20}$ & 5.6 \\
\hline 0.520 & & 0.517 & $f_{23}$ & 0.5 \\
\hline
\end{tabular}

than those for the vertical and torsional motions. Therefore, it should be kept in mind that the accuracy of the experimental measurements for the lateral deck modes could be less than those for the torsional and vertical deck modes.

Only one deck mode observed in the measurements had no counterpart in this FE calculation; mode L3 measured by Brownjohn et al. [1] in their experimental study did not occur in the current analysis. The FE studies done by Dumanoglu et al. [3] and Apaydin [5] also did not find a mode that corresponded to the measured mode L3. The mode shape L3 was identical to the mode shape L2, and the two frequencies were close to each other [1]. Note that all other modes of the deck, towers, and cables that were clearly identified by Brownjohn et al. were also found in the current numerical study.

\subsection{Torsional Deck Modes}

Figure 8 depicts the first torsional deck mode $f_{11}$. The deck rotation and vertical cable motion were synchronous. The experimental and numerical analysis results clearly showed these modes. Table 4 presents the close agreement (frequency
Table 4 Comparison of calculated torsional deck modes with experimental results

\begin{tabular}{|c|c|c|c|c|}
\hline \multicolumn{2}{|c|}{ Measured modes } & \multicolumn{2}{|c|}{$\underline{\text { Numerical analysis }}$} & \multirow{2}{*}{$\begin{array}{l}\text { Rel. error } \\
(\%)\end{array}$} \\
\hline$f_{\exp }(\mathrm{Hz})$ & Mode & $f_{\text {num }}(\mathrm{Hz})$ & Mode & \\
\hline 0.296 & $\mathrm{~T} 1$ & 0.290 & $f_{11}$ & 2.1 \\
\hline 0.352 & $\mathrm{~T} 2$ & 0.347 & $f_{14}$ & 1.5 \\
\hline 0.529 & $\mathrm{~T} 3$ & 0.526 & $f_{24}$ & 0.6 \\
\hline 0.692 & $\mathrm{~T} 4$ & 0.715 & $f_{38}$ & -3.3 \\
\hline 0.867 & $\mathrm{~T} 5$ & 0.856 & $f_{44}$ & 1.2 \\
\hline 1.036 & T6 & 1.018 & $f_{66}$ & 1.7 \\
\hline 1.200 & & 1.182 & $f_{89}$ & 1.5 \\
\hline 1.260 & & 1.324 & $f_{112}$ & -5.1 \\
\hline 1.350 & & 1.380 & $f_{116}$ & 2.2 \\
\hline 1.500 & & 1.494 & $f_{129}$ & 0.4 \\
\hline
\end{tabular}

Table 5 Comparison of calculated vertical deck modes with experiments

\begin{tabular}{|c|c|c|c|c|}
\hline \multicolumn{2}{|c|}{ Measured modes } & \multicolumn{2}{|c|}{ Numerical analysis } & \multirow{2}{*}{$\begin{array}{l}\text { Rel. error } \\
(\%)\end{array}$} \\
\hline$f_{\exp }(\mathrm{Hz})$ & Mode & $f_{\text {num }}(\mathrm{Hz})$ & Mode & \\
\hline \multirow[t]{3}{*}{0.125} & V1 & 0.106 & $f_{2}$ & $(15.1)$ \\
\hline & & 0.127 & $f_{\text {mean }}$ & -1.6 \\
\hline & & 0.148 & $f_{3}$ & $(-18.7)$ \\
\hline 0.155 & V2 & 0.155 & $f_{4}$ & -0.1 \\
\hline 0.208 & V3 & 0.206 & $f_{5}$ & 0.8 \\
\hline 0.244 & V4 & 0.247 & $f_{7}$ & -1.3 \\
\hline 0.317 & V5 & 0.319 & $f_{13}$ & -0.6 \\
\hline 0.389 & V6 & 0.390 & $f_{15}$ & -0.4 \\
\hline 0.470 & V7 & 0.469 & $f_{19}$ & 0.2 \\
\hline 0.555 & V8 & 0.551 & $f_{31}$ & 0.6 \\
\hline 0.645 & V9 & 0.639 & $f_{34}$ & 0.9 \\
\hline 0.741 & V10 & 0.730 & $f_{39}$ & 1.4 \\
\hline 0.839 & V11 & 0.826 & $f_{43}$ & 1.6 \\
\hline 0.942 & V12 & 0.924 & $f_{55}$ & 1.9 \\
\hline 1.040 & & 1.025 & $f_{67}$ & 1.4 \\
\hline 1.150 & & 1.128 & $f_{85}$ & 1.9 \\
\hline 1.255 & & 1.233 & $f_{98}$ & 1.8 \\
\hline 1.380 & & 1.339 & $f_{113}$ & 3.0 \\
\hline
\end{tabular}

errors of less than $5.1 \%$ ) with measured results up to modes with frequencies of $1.5 \mathrm{~Hz}$.

\subsection{Vertical Deck Modes}

The first two vertical deck mode shapes $f_{2}$ and $f_{5}$ are shown in Figs. 9 and 10. Table 5 compares the measured and calculated eigenfrequencies for these modes up to $1.38 \mathrm{~Hz}$; the relative errors for all but one mode were below $3.0 \%$. Only the first vertical mode V1 of the ambient vibration study [1] had two numerical counterparts of $f_{2}$ and $f_{3}$ in the current 


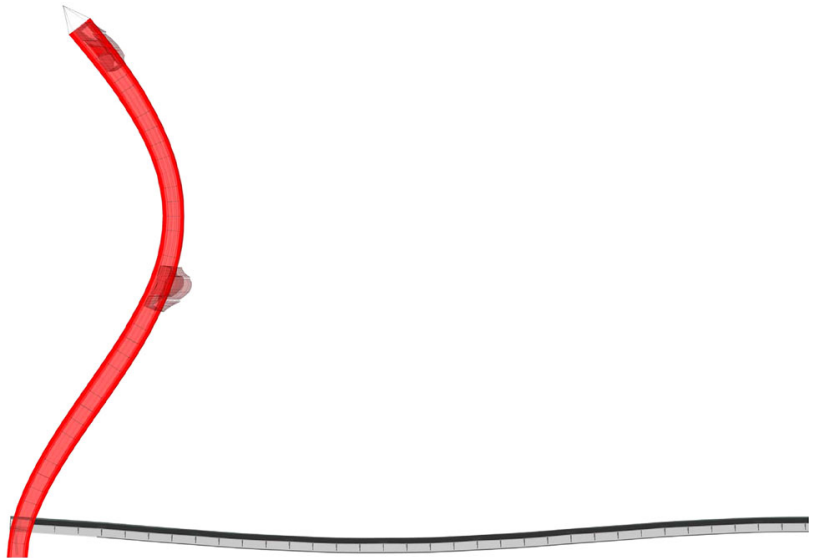

Fig. 11 Mode $f_{99}$, Freq. 1.239 Hz: synchronous longitudinal tower motion, displacements are scaled to show the characteristics of the modes

analysis. Both were vertical antisymmetric deck modes coupled with the longitudinal motion of the deck in opposite directions. In the experiment, only the vertical motion was measured, and frequencies were clearly identified. The corresponding longitudinal motion was not measured, so the two modes could not be resolved in this experiment. Other analysts have also determined the two corresponding modes in $2 \mathrm{D}$ and $3 \mathrm{D}$ analyses $[3,5]$. Brownjohn et al. tried to solve the discrepancy by analyzing a model fixed in the longitudinal direction. However, this condition is in contrast to the bridge support. The calculated frequencies of $f_{2}$ and $f_{3}$ were 0.106 and $0.148 \mathrm{~Hz}$, respectively. Physically, the superposition of two adjacent waves with similar mode shapes is referred to as the beat effect [20], which occurred with the mean frequency $f_{\text {mean }}=0.127 \mathrm{~Hz}$. The small modulation of the amplitude of the interfering waves changed with the modulation frequency of $f_{\text {mod }}=\Delta f / 2=0.02 \mathrm{~Hz}$, which corresponded to a period of $50 \mathrm{~s}$. Such a long period made it difficult to detect the beat effect in the ambient vibration measurements.

\subsection{Longitudinal Tower Modes}

Figures 11 and 12 depict the longitudinal tower modes. The high forces of the cables constrained the longitudinal motion of the tower tip. No pure cantilever mode was found to have a significant amplitude; there were only the higher modes of a beam clamped at the bottom and fixed at the top. The two vertical pylon beams could move synchronously (e.g., mode $f_{99}$ in Fig. 11) or asynchronously (e.g., mode $f_{112}$ in Fig. 12). Asynchronous motion produced torque of the tower about the vertical axis.

Table 6 compares the experimental data for synchronous tower motion. The modes $f_{4}, f_{5}, f_{13}$, and $f_{39}$ were coupled with the dominant vertical deck motion, so their mode shapes were not discussed by Brownjohn et al. [1]. How-

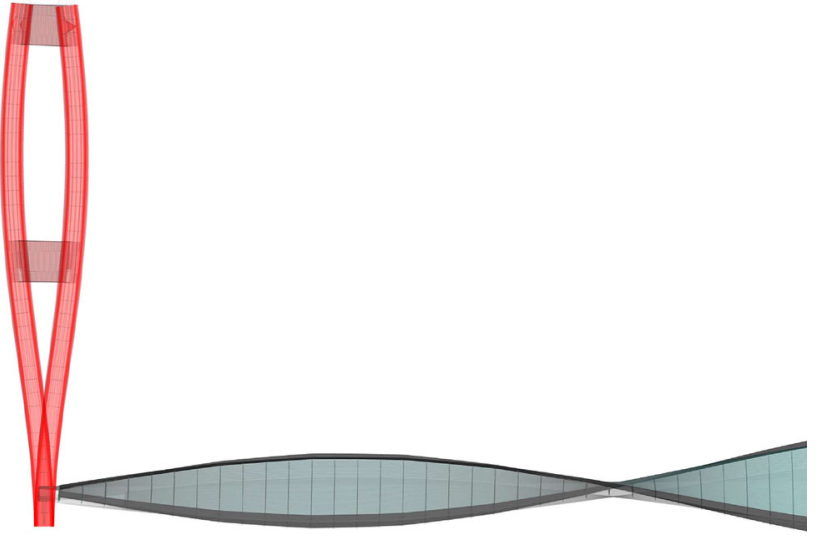

Fig. 12 Mode $f_{112}$, Freq. $1.32 \mathrm{~Hz}$ : asynchronous longitudinal tower motion, displacements are scaled to show the characteristics of the modes

Table 6 Comparison of calculated pure bending longitudinal tower modes with experiments

\begin{tabular}{|c|c|c|c|c|}
\hline \multicolumn{2}{|c|}{ Measured modes } & \multicolumn{2}{|c|}{$\underline{\text { Numerical analysis }}$} & \multirow{2}{*}{$\begin{array}{l}\text { Rel. erro } \\
(\%)\end{array}$} \\
\hline$f_{\exp }(\mathrm{Hz})$ & Mode & $f_{\text {num }}(\mathrm{Hz})$ & Mode & \\
\hline 0.160 & & 0.155 & $f_{4}$ & 3.1 \\
\hline 0.210 & & 0.206 & $f_{5}$ & 1.9 \\
\hline 0.320 & & 0.319 & $f_{13}$ & 0.3 \\
\hline 0.760 & & 0.730 & $f_{39}$ & 3.9 \\
\hline 1.154 & TV5 & 1.128 & $f_{85}$ & 2.3 \\
\hline 1.265 & TV6 & 1.233 & $f_{98}$ & 2.5 \\
\hline 1.280 & TV7 & 1.239 & $f_{99}$ & 3.2 \\
\hline 1.420 & TV9 & 1.310 & $f_{111}$ & 7.7 \\
\hline 1.538 & TV11 & 1.462 & $f_{127}$ & 4.9 \\
\hline 1.580 & TV13 & 1.552 & $f_{139}$ & 1.8 \\
\hline
\end{tabular}

ever, the corresponding resonance frequencies could easily be identified by using the auto power spectrum plots. All modes with frequencies below $1 \mathrm{~Hz}$ showed an out-of-phase motion for which the towers on the opposite sides of the Bosporus moved in opposite directions. The first mode with an in-phase motion was $f_{99}$ with a frequency of $1.239 \mathrm{~Hz}$. The in-phase motion resulted in an increased contribution of the modal mass to the longitudinal motion, as discussed in the Sect. 5.

Table 7 presents the close agreement between the calculated and measured modes for the asynchronous tower motion. Again, the measured frequencies had to be taken from the auto power spectrum plots because the corresponding mode shapes were not discussed by Brownjohn et al. [1].

\subsection{Lateral Tower Modes}

For the lateral response, the motion of the top of the towers was not constrained by the suspension cables. Figure 13 
Table 7 Comparison of calculated longitudinal tower modes with experiments for modes with bending and torque

\begin{tabular}{|c|c|c|c|c|}
\hline \multicolumn{2}{|c|}{ Measured modes } & \multicolumn{2}{|c|}{ Numerical analysis } & \multirow{2}{*}{$\begin{array}{l}\text { Rel. error } \\
(\%)\end{array}$} \\
\hline$\overline{f_{\exp }(\mathrm{Hz})}$ & $\overline{\text { Mode }}$ & $\overline{f_{\text {num }}(\mathrm{Hz})}$ & Mode & \\
\hline 0.30 & & 0.290 & $f_{11}$ & 2.7 \\
\hline 1.03 & & 1.018 & $f_{71}$ & 1.1 \\
\hline 1.35 & & 1.324 & $f_{112}$ & 1.9 \\
\hline 1.41 & & 1.380 & $f_{116}$ & 2.1 \\
\hline 1.52 & & 1.494 & $f_{129}$ & 1.7 \\
\hline 1.58 & & 1.543 & $f_{138}$ & 2.3 \\
\hline
\end{tabular}

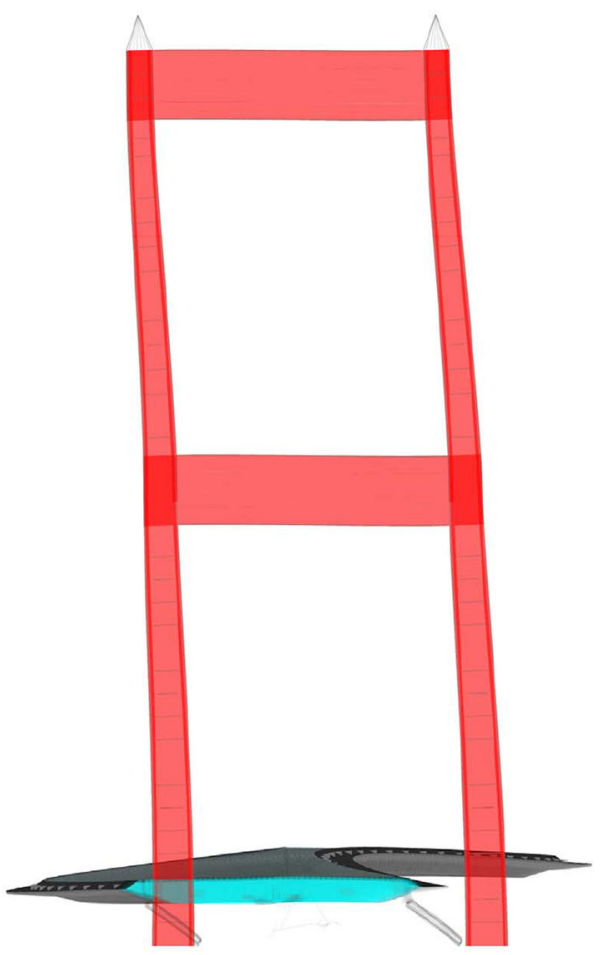

Fig. 13 Mode $f_{16}$, Freq. $0.398 \mathrm{~Hz}$ : lateral tower motion-basic cantilever mode, displacements are scaled to show the characteristics of the modes

shows the lateral motion of the tower with the basic cantilever mode $f_{16}$, and Fig. 14 shows that with the higher mode $f_{157}$. Table 8 lists the frequencies of the lateral tower modes. In the lateral tower modes with low frequencies, the tower tip moved in the lateral direction (Fig. 13) and excited the lateral deck motion.

\section{Modal Mass Analysis}

Different modes are important depending on the objective. Cable modes are important for excitation by an aerodynamic drag load. The lateral, vertical, and torsional modes of the deck and tower are important to analyzing the displacement

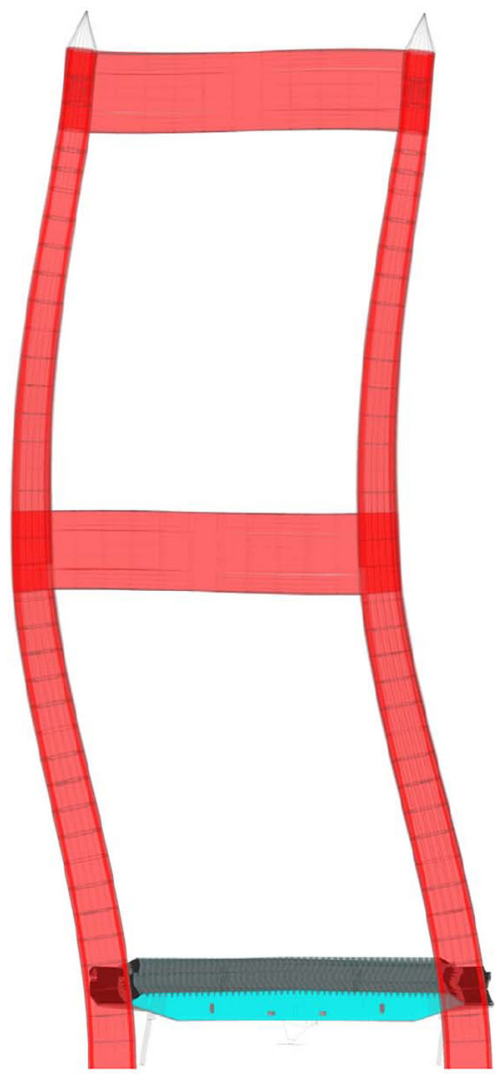

Fig. 14 Mode $f_{157}$, Freq. $1.657 \mathrm{~Hz}$ : lateral tower motion-higher order mode, displacements are scaled to show the characteristics of the modes

Table 8 Comparison of calculated lateral tower modes with experimental results

\begin{tabular}{|c|c|c|c|c|}
\hline \multicolumn{2}{|c|}{ Measured modes } & \multicolumn{2}{|c|}{ Numerical analysis } & \multirow{2}{*}{$\begin{array}{l}\text { Rel. error } \\
(\%)\end{array}$} \\
\hline$f_{\exp }(\mathrm{Hz})$ & Mode & $f_{\text {num }}(\mathrm{Hz})$ & Mode & \\
\hline 0.287 & TL1 & 0.286 & $f_{9}$ & 0.3 \\
\hline 0.295 & TL2 & 0.295 & $f_{12}$ & 0.0 \\
\hline 0.385 & & 0.398 & $f_{16}$ & -3.4 \\
\hline 0.432 & TL3 & 0.468 & $f_{18}$ & -8.3 \\
\hline 0.464 & TL4 & 0.476 & $f_{20}$ & -2.6 \\
\hline 0.503 & TL5 & 0.509 & $f_{22}$ & -1.2 \\
\hline 0.520 & TL6 & 0.517 & $f_{23}$ & 0.6 \\
\hline 0.630 & TL7 & 0.601 & $f_{32}$ & 3.4 \\
\hline 0.673 & TL8 & 0.678 & $f_{35}$ & -0.7 \\
\hline 0.692 & TL9 & 0.686 & $f_{36}$ & 0.9 \\
\hline 0.753 & TL10 & 0.767 & $f_{40}$ & -1.9 \\
\hline 0.802 & TL11 & 0.825 & $f_{42}$ & -2.9 \\
\hline 0.866 & TL12 & 0.881 & $f_{45}$ & -1.7 \\
\hline 0.937 & TL13 & 0.955 & $f_{56}$ & -1.9 \\
\hline 1.200 & TL17 & 1.154 & $f_{87}$ & 3.8 \\
\hline 1.370 & TL20 & 1.369 & $f_{115}$ & 0.1 \\
\hline 1.712 & TL26 & 1.691 & $f_{163}$ & 1.2 \\
\hline
\end{tabular}


Table 9 Transitional modal masses of eigenmodes with contributions greater than $5 \%$ of total mass

\begin{tabular}{lllll}
\hline Mode & Freq. $(\mathrm{Hz})$ & \multicolumn{4}{c}{ Effective modal mass $(\%)$} \\
\cline { 3 - 5 } & & $x$-trans. & $y$-trans. & $z$-trans. \\
\hline$f_{1}$ & 0.072 & 61.07 & - & - \\
$f_{2}$ & 0.106 & - & 27.20 & - \\
$f_{3}$ & 0.148 & - & 29.23 & - \\
$f_{4}$ & 0.156 & - & - & 20.28 \\
$f_{5}$ & 0.206 & - & - & 41.55 \\
$f_{16}$ & 0.398 & 9.73 & - & - \\
$f_{22}$ & 0.509 & 10.04 & - & - \\
$f_{29}$ & 0.550 & - & - & 6.75 \\
$f_{99}$ & 1.239 & - & 29.80 & - \\
$\sum$ & & & & \\
\hline
\end{tabular}

and stresses of the bridge structure. The effective mass allows the significance of a mode to be quantified. Table 9 lists the effective masses (as percentages of the total mass of the FSM Bridge) of the important modes for synchronous excitations of both towers. Symmetric lateral, vertical, and longitudinal modes contributed to the effective mass.

Modes with transitional modal masses larger than 5\% of the total mass are included in Table 9. The first five modes, which are deck modes, contained more than $50 \%$ of the effective mass in each direction. Modes up to $0.509 \mathrm{~Hz}$ needed be calculated in order to reach $80 \%$ of the effective modal mass in the lateral direction ( $x$-direction) as listed on the line ' $\sum$ modal masses'. For the longitudinal direction ( $y$-direction), modes with frequencies up to $1.239 \mathrm{~Hz}$ needed be analyzed to incorporate $80 \%$ of the effective mass. Vertical modes up to $0.55 \mathrm{~Hz}$ contributed more than $5 \%$ in the $z$-direction. In order to include $80 \%$ of the total effective mass in the $z$ direction, three modes with single contributions below $5 \%$ had to be considered. One of these modes had a frequency higher than $10 \mathrm{~Hz}$ owing to the stiff response of the towers in the vertical direction.

The coupled lateral deck tower modes $f_{16}$ and $f_{22}$ contributed to the lateral modal mass because they were symmetric. Only one cable mode with a frequency of $0.55 \mathrm{~Hz}$ had a significant modal mass, which had its origin in the synchronous symmetric vertical swinging of all back-stay cables, but it was not important to the structural properties of the FSM Bridge. Mode $f_{99}$ with a frequency of $1.239 \mathrm{~Hz}$ was the only tower mode with significant modal mass in the longitudinal direction. As pointed out in the Sect. 4.4, this was due to the synchronous longitudinal motion in this mode; all lower longitudinal tower modes were asynchronous, which led to the cancellation of the modal masses.

Several previous studies focused on describing the first 40 eigenmodes up to $0.8 \mathrm{~Hz}$. Based on the modal masses, the first
40 modes were not sufficient to capture all of the important modal mass contributions. That is, the accumulated modal mass was well below $80 \%$ of the physical total mass in two directions. In fact, the eigenmodes needed to be computed with frequencies up to $11 \mathrm{~Hz}$ in order to reach an accumulated modal mass of around $90 \%$ in all three directions.

\section{Comparison of Beam and Shell FE Models for Torsional Modes of the FSM Bridge}

In order to illustrate the difficulty in modeling the orthotropic deck structure of the FSM Bridge using beam elements, Table 8 provides the comparison of modal frequencies between the ambient vibration test results [1] and the calculations of the FE models for the torsional modes T1 through T5. The beam FE model included the deck, tower, and rocker bearings of the FSM Bridge [5,6]. The shell FE model of this study provided closer results to the ambient vibration test measurements for all the modes given in Table 10. The relative error of the beam model was at least one order of magnitude higher than the shell model. The orthotropic deck structure with internal diaphragms and stiffeners were only approximately represented by a single torsional constant in the cross-sectional input properties of the beam model, whereas the shell model included such structural components explicitly in the analysis of the bridge.

\section{Conclusions and Recommendations for Future Work}

Modeling all of the thin steel plates of a structure with shell elements and the cables with beam elements is a straightforward procedure to generate a model from structural design documents. The analysis showed that this approach provided a high-fidelity model of the suspension bridge. Modern FE tools allow the efficient generation and solution of this large model. The LS-DYNA commercial finite element code was used to investigate the free vibration modes of the FSM Suspension Bridge. No effective cross-sections need to be estimated or fitted to the experimental results. All major stiffener plates and load-carrying structural components are included. The parameter-free FE model removes the need for calibration when compared with the beam models of suspension bridges that require the iterative calibration of the cross-sectional area, moments of inertia, and torsional constants. In contrast to beam models, the proposed model includes the deck cross-sectional deformations caused by the rocker bearings and wind shoes. All of the natural frequencies of the bridge for lateral, vertical, longitudinal, and torsional behaviors can be calculated with this 3D model with good accuracy into the high frequency range. The benefit of the 
Table 10 Comparison of torsional mode frequencies for the shell and beam FE models

\begin{tabular}{llllll}
\hline $\begin{array}{l}\text { Torsional } \\
\text { mode number }\end{array}$ & $\begin{array}{l}\text { Measured ambient } \\
\text { vibration freq. }(\mathrm{Hz})\end{array}$ & $\begin{array}{l}\text { Shell model com- } \\
\text { puted freq. }(\mathrm{Hz})\end{array}$ & $\begin{array}{l}\text { Rel. error of shell } \\
\text { model }(\%)\end{array}$ & $\begin{array}{l}\text { Beam model } \\
\text { computed freq. } \\
(\mathrm{Hz})\end{array}$ & $\begin{array}{l}\text { Rel. error of beam } \\
\text { model }(\%)\end{array}$ \\
\hline T1 & 0.296 & 0.290 & 2.1 & 0.387 & -31 \\
T2 & 0.352 & 0.347 & 1.5 & 0.417 & -19 \\
T3 & 0.526 & 0.6 & 0.633 & -20 \\
T4 & 0.692 & 0.715 & -3.3 & 0.799 & -16 \\
T5 & 0.867 & 0.856 & 1.2 & 1.026 & -18 \\
\hline
\end{tabular}

model is that all coupling effects between different modes and the different components of the deck, towers, and cables are automatically included, while the limited number of sensors placed on the structure makes identifying coupled modes in an experiment challenging.

The comparison of the calculated coupled modes and experimental results led to a better understanding of the physical behavior of the bridge, as shown for the deck and tower modes. There is only a single measured mode that corresponds to the calculated frequencies of the modes $f_{2}$ and $f_{3}$. The discrepancy was attributed to the superposition of these two modes via the beat effect, as discussed in the Sect. 4.3. The ambient vibration measurements were carried out under weak wind conditions, which resulted in weak amplitudes for the lateral modes as discussed in the Sect. 4.1. Therefore, the accuracy of the measured frequencies was less for the lateral modes of the deck, while the calculated vertical and torsional deck mode frequencies were reproduced with relative errors below roughly $5 \%$. All tower mode frequencies fit the measured values with relative errors of less than $9 \%$. Contrast between the beam and shell FE models of the bridge was demonstrated for the results of the torsional mode frequencies.

Using the effective modal mass as a criterion for important modes made it clear that modes up to a frequency of around 1.2 Hz must be identified when analyzing the dynamic behavior with modal superposition methods. A single mode with a frequency of $1.24 \mathrm{~Hz}$ had an effective modal mass contribution of about $30 \%$ of the total mass and was a longitudinal tower mode that occurred at a high frequency due to the high axial forces of the suspension and back-stay cables. Only a model that includes the stiffened structure of the towers and the realistic cable forces at the same time can describe such an important mode.

This model can be used with not only the response spectrum approach and modal superposition method but also in nonlinear time history analyses with explicit time integration. The detailed model resolves local stress concentrations in the deck and tower components to identify fatigue damage and localized plastic strain under extreme loads. The next phase of the study will involve using the developed model as an approved basis for further nonlinear seismic analysis of the FSM Bridge, such as investigating severe events where the deck and towers are impacted.

Acknowledgements The first author is grateful to the funding provided by TUBITAK (Turkish Scientific and Technological Research Council) through research Grant 107M002 and by the Bogazici University Research Fund through Contract 07HT102.

Open Access This article is distributed under the terms of the Creative Commons Attribution 4.0 International License (http://creativecomm ons.org/licenses/by/4.0/), which permits unrestricted use, distribution, and reproduction in any medium, provided you give appropriate credit to the original author(s) and the source, provide a link to the Creative Commons license, and indicate if changes were made.

\section{References}

1. Brownjohn, J.M.W.; Dumanoglu, A.A.; Severn, R.T.: Ambient vibration survey of the Fatih Sultan Mehmet (Second Bosporus) suspension bridge. Earthq. Eng. Struct. D. 21, 907-24 (1992)

2. Brownjohn, J.M.W.; Severn, R.T.; Dumanoglu, A.A.: Full-scale dynamic testing of the 2nd Bosporus suspension bridge. In: Proceedings of the Tenth World Conference on Earthquake Engineering, Madrid, Spain, pp. 2695-700 (1992)

3. Dumanoglu, A.A.; Brownjohn, J.M.W.; Severn, R.T.: Seismic analysis of the Fatih Sultan Mehmet (2nd Bosporus) suspension bridge. Earthq. Eng. Struct. D. 21, 881-906 (1992)

4. Abdel-Ghaffar, A.M.; Stringfellow, R.G.: Response of suspension bridges to travelling earthquake excitations: part II. Lateral response. Soil Dyn. Earthq. Eng. 3, 73-81 (1984)

5. Apaydin, N.M.: Seismic analysis of Fatih Sultan Mehmet Suspension Bridge. Ph.D. thesis, Department of Earthquake Engneering, Bogazici University, Istanbul, Turkey (2002)

6. Apaydin, N.M.: Earthquake performance assessment and retrofit investigations of two suspension bridges in Istanbul. Soil Dyn. Earthq. Eng. 30, 702-10 (2010)

7. Daniell, W.E.; Macdonald, J.H.G.: Improved finite element modelling of a cable-stayed bridge through systematic manual tuning. Eng. Struct. 29, 358-71 (2007)

8. Zhang, J.; Prader, J.; Moon, F.; Aktan, E.; Wu, Z.S.: Challenges and strategies in structural identification of a long span suspension bridge. In: 6th International Workshop on Advanced Smart Materials and Smart Structures Technology (ANCRiSST), Dalian, pp $1-12(2011)$

9. Rahbari, A.R.; Brownjohn, J.M.W.: Finite element modelling of Humber Bridge. In: 6th International Conference on Bridge Main- 
tenance, Safety and Management (IABMAS), Stresa, pp. 3709-16 (2012)

10. Karmakar, D.; Ray-Chaudhuri, S.; Shinozuka, M.: Finite element model development, validation and probabilistic seismic performance evaluation of Vincent Thomas suspension bridge. Struct. Infrastruct. E. 11(2), 223-237 (2015)

11. Duan, Y.F.; Xu, Y.L.; Fei, Q.G.; Wong, K.Y.; Chan, K.W.Y.; Ni, Y.Q.; Ng, C.L.: Advanced finite element model of Tsing Ma Bridge for structural health monitoring. Int. J. Struct. Stab. Dyn. 11, 313$344(2011)$

12. Hallquist, J.O.: LS-DYNA Theory Manual. LSTC (Livermore Software Technology Corporation), Livermore, California (2006)

13. IHI, MHI, NKK Corp.: Record Book for the Fatih Sultan Mehmet Suspension Bridge. Tokyo (1989)

14. Ingenlath, P.: Seismic Finite Element Analysis of the Second Bosporus Bridge. Bachelor Engineering thesis, Department of Mechanical Engineering, Aachen University of Applied Sciences, Aachen (2010)

15. Belytschko, T.B.; Tsay, C.S.: Explicit algorithms for the nonlinear dynamics of shells. Comput. Method. Appl. Mech. Eng. 42, 225$251(1984)$
16. Hughes, T.J.R.; Liu, W.K.: Nonlinear finite element analysis of shells: part I. Three-dimensional shells. Comput. Method. Appl. Mech. Eng. 26, 331-362 (1981)

17. Hughes, T.J.R.; Liu, W.K.: Nonlinear finite element analysis of shells: part II. Two-dimensional shells. Comput. Method. Appl. Mech. Eng. 27, 167-181 (1981)

18. Grimes, R.; Lewis, J.; Simon, H.: A shifted block Lanczos algorithm for solving sparse symmetric generalized eigenproblems. SIAM J. Matrix Anal. Appl. 15, 228-272 (1994)

19. The Boeing Company: Boeing Extreme Mathematical Library (BCSLIB-EXT) User's Guide. Seattle, Washington (2000)

20. Feynman, R.P.; Sands, M.; Leighton, R.: The Feynman Lectures on Physics. Addison Wesley, Boston (2006) 